\title{
PARODIA, SIMULACIÓN Y CANIBALISMO EN "HECHOS DE UN BUEN CIUDADANO I" Y "HECHOS DE UN BUEN CIUDADANO II” DE CLAUDIA HERNÁNDEZ
}

Virginia Caamaño Morúa

\section{(c)}

Esta obra está bajo una licencia Creative Commons

Reconocimiento-No Comercial-Sin Obra Derivada 



\title{
PARODIA, SIMULACIÓN ${ }^{1}$ Y CANIBALISMO EN "HECHOS DE UN BUEN CIUDADANO I" Y "HECHOS DE UN BUEN CIUDADANO II" DE CLAUDIA HERNÁNDEZ ${ }^{2}$
}

\author{
PARODY, SIMULATION AND CANNIBILISM IN "ACTIONS BY A GOOD \\ CITIZEN I" AND “ACTIONS OF A GOOD CITIZEN II" BY CLAUDIA \\ HERNANDEZ
}

\author{
Virginia Caamaño Morúa
}

\begin{abstract}
RESUMEN
En este estudio se analizan los cuentos de la salvadoreña Claudia Hernández "Hechos de un buen ciudadano I" y "Hechos de un buen ciudadano II" a partir de la estética fantástica sostenida en la parodia, el absurdo y la simulación. Lo paródico aparece como una nueva forma de realismo donde se expone una realidad concreta: un Estado de derecho simulado, en el cual se invisibilizan situaciones de brutalidad y violencia que afectan a los habitantes de esa sociedad. La violencia es representada en los numerosos cadáveres que aparecen en las casas y en la ocurrencia de otros hechos grotescos y siniestros, vistos como normales por todos los personajes. El "buen ciudadano", protagonista de los textos, en armonía con la sociedad donde vive, simula ser un buen hombre, sin embargo, su narración y actuaciones lo descubren al final como un monstruo.

Palabras clave: literatura fantástica, literatura latinoamericana, literatura centroamericana, parodia, canibalismo.
\end{abstract}

\begin{abstract}
This paper analyzes two stories by Salvadorian author Claudia Hernández, "Hechos de un buen ciudadano I" and "Hechos de un buen ciudadano II" ("Incidents of a good citizen I" and "Incidents of a good citizen II") from the point of view of the aesthetics of fantasy, which is sustained through parody, absurd and simulation. Parody appears as a new form of realism, where a concrete reality is exposed: a State that simulates to be governed by the rule of law, and hides situations of brutality and violence affecting its inhabitants. Violence is represented by the numerous corpses that appear in houses, and by some other grotesque and sinister events that all characters see as normal. The "good citizen", protagonist in the stories, in harmony with his society, pretends to be a good man, however, his narration and deeds finally reveal him as a monster.
\end{abstract}

Key words: fantastic literature, Latin American literature, Central América literature, parody, cannibalism.

\footnotetext{
M.L. Virgina Caamaño Morúa. Universidad de Costa Rica. Profesora catedrática e investigadora en la Escuela de Filología, Lingüística y Literatura; en la Maestría de Literatura y en el Programa de Investigaciones Literarias. Costa Rica.

Correo electrónico: vicaamano@yahoo.com
}

Recepción: 05- 02- 2015

Aceptación: 19- 06- 2015 
[...] el primer monstruo identificado y calificado, no es el asesino, no es el violador, no es quien rompe las leyes de la naturaleza; es quien quiebra el pacto social fundamental.

(Foucault, 2011, p. 96)

Me escandalizó que mi amigo rechazara el caso de Wilhem Storitz; si alguien había escrito sobre un hombre invisible, ¿no bastaba para que su existencia fuera irrefutablemente posible?

(Cortázar, 1972, pp. 70-71)

\section{Introducción}

En su estudio de la estética fantástica contemporánea, el teórico español David Roas propone que lo fantástico surge cuando un orden de sucesos rompe las reglas establecidas para comprender la realidad del mundo conocido, produciendo inestabilidad e inquietud en el público lector (cfr. Roas, 2011), pero no en los personajes, quienes muy a menudo consideran normal lo ocurrido. Esta ausencia de reacción pone en escena, según Roas, una de las características de lo fantástico posmoderno: la normalización de los hechos sobrenaturales por parte de los personajes, lo cual aparece como un rasgo distintivo en los relatos de la escritora salvadoreña Claudia Hernández (2007) "Hechos de un buen ciudadano I" y "Hechos de un buen ciudadano II", 3 objeto de este trabajo, donde una serie de muertes violentas no explicadas son asumidas con normalidad por los personajes, creándose cierta atmósfera fantástica, que es considerada en este acercamiento parodia de una realidad extratextual.

Otro de los estudiosos de esa estética es el venezolano Víctor Bravo, quien considera lo fantástico como insostenible, pues conduce a la locura. Según su criterio, lo fantástico solo logra mantenerse en el discurso paródico, en el cual surge como una nueva forma de realismo, que al mismo tiempo lo niega como tal. Este discurso paródico aparece a través de lo hiperbólico, lo escatológico o con el empleo de la digresión (cfr. Bravo, 1988). Por eso lo fantástico necesariamente sigue dos caminos: se resuelve en asombro y se transforma en horror, o bien en la ausencia de asombro que lleva al establecimiento del absurdo; tanto el horror, que se manifiesta generalmente como expresión del mal, como el absurdo, tienen una salida en la irrisión (cfr. Bravo, 1988).

Con el interés de determinar cómo es representada esta estética en los textos mencionados y analizar las estrategias de la autora para lograr ese fin, realizo el abordaje de los cuentos a partir de las propuestas de Roas y Bravo explicadas y las de la crítica británica Rosie Jackson (2001), ${ }^{4}$ quien identifica lo fantástico con lo irracional, que viene a manifestarse como un tipo de lenguaje del inconsciente, por lo tanto lo ve como lo "otro", 'lo oculto' de la cultura. Para Jackson, eso 'oculto' brota como una especie de oposición social sediciosa y perturbadora, enfrentado a la ideología dominante de su época, que muestra lo no visto y lo no dicho de esa cultura al exponer un hecho imposible dentro de ella, convirtiéndose de ese modo, en subversivo.

También acudo a la noción de "Lo siniestro", la cual continúa apareciendo frecuentemente en la estética fantástica contemporánea y que fue definida por Freud (1981, p. 2484) como "aquella suerte de espantoso que afecta las cosas conocidas y familiares desde tiempo atrás". 5 Cuando surge, rompe la cotidianeidad y el sentido de seguridad que existía y deja en evidencia el límite que hay entre la realidad y lo imposible, precipitando la irrupción de lo fantástico (cfr. Roas, 2001). 
Los aportes expuestos arriba son imprescindibles para realizar el abordaje de los relatos de Hernández, donde el tema de la violencia a partir de una de sus consecuencias fundamentales, la muerte por homicidio, es el eje fundamental alrededor del cual se teje la narración y así se apreciará en el análisis.

\section{Los muertos y su significado}

El tratamiento que el homicidio recibe en las narraciones es muy peculiar y probablemente produzca en el público lector una sensación de inquietud y malestar ante las incógnitas sin respuesta y el horror de lo ocurrido, así como de asombro ante la normalidad y ligereza con que los personajes acogen los hechos. Situación irregular e increíble desde nuestros parámetros de lo que significa vivir en una sociedad donde hay leyes que exigen, en primer lugar, el respeto de la vida humana y disponen castigar a todo aquel que las viole. Lo sucedido en la sociedad plasmada en estos cuentos se opone a la razón y desde esa perspectiva, puede juzgarse "antinatural", "anormal" o "fantástico".

En este estudio, la escenificación de estas muertes violentas es interpretada como una señal que atrae la atención hacia ciertos episodios ocurridos durante los conflictos ideológicos, sociales, económicos y culturales experimentados en El Salvador durante buena parte del siglo XX. Uno de los episodios más críticos -vivido por la autora en su infancia y adolescencia- es la abierta guerra civil que asola el país durante doce años, ocasionando millares de muertos y desaparecidos que la sociedad civil no pudo evitar.

Como es sabido, en la literatura se plasman muchos de los fenómenos que transforman y marcan de diferentes maneras las sociedades, apareciendo como síntomas de lo sucedido y así lo he expuesto en otros trabajos. ${ }^{6}$ En "Hechos de un buen ciudadano I" y "Hechos de un buen ciudadano II" los muertos son tan numerosos que aparecen hasta en el interior de las casas de habitación. Se manifiestan como indicios de eso "oculto' de la cultura" (cfr. Jackson, 2001), que viene a subvertir las versiones oficiales sobre lo sucedido y nombran lo silenciado exponiéndolo, con el fin de conjurarlo.

Al referirse al libro De fronteras y a los cuentos en estudio, el escritor Rafael Menjívar dice que:

\footnotetext{
Hay quienes han querido encontrar en los relatos de este libro una visión metafórica de El Salvador de la última etapa de la guerra y de posguerra, y no se trata de una hipótesis desacertada; la aparente locura de sus situaciones y personajes, contrastada con la realidad salvadoreña, a veces parecería más un retrato en sepia que una invención. (Menjívar, 2007, párr. 4)
}

De acuerdo con numerosos estudios históricos y sociológicos realizados sobre la situación salvadoreña ${ }^{7}$ y recreada en textos literarios ${ }^{8}$ escritos en diversos géneros, históricamente ha existido una amplia brecha entre ricos y pobres mantenida a lo largo del tiempo por un sistema represivo administrado por el ejército, que en alianza con la oligarquía irrespeta los resultados del sufragio popular en varias ocasiones. Estos sucesos agudizan el malestar social general y provocan un clima hostil, con enfrentamientos entre los distintos grupos, identificados de derecha y de izquierda, que desemboca a menudo en una violencia indiscriminada. Con el objetivo de frenar esa situación, a fines de los años 70 se intenta establecer un pacto entre un grupo muy heterogéneo de fuerzas con los militares, pero no logra progresar porque estos últimos no quieren ceder el control del poder (cfr. Fonseca, 1998). 
La represión y los crímenes contra la población continúan en aumento hasta el asesinato de monseñor Oscar Arnulfo Romero en marzo de 1980, acto que desencadena una mayor agresión, destrucción y brutalidad entre las fuerzas en conflicto, como señala al respecto el Informe de la Comisión de la Verdad: ${ }^{9}$

Este crimen polarizó aún más a la sociedad salvadoreña y se convirtió en hito que simboliza el mayor
irrespeto por los derechos humanos y preludio de la guerra abierta entre gobierno y guerrillas. Durante
los funerales, estalla una bomba frente a la Catedral de San Salvador, la multitud estimada en 50,000
personas, presa del pánico es ametrallada. (s.f., p. 34)

A partir de ese momento, una amplia coalición de organizaciones forma el Frente Democrático Revolucionario y unos meses después se funda el Frente Farabundo Martí para la Liberación Nacional,

\begin{abstract}
con base en cinco organizaciones populares que ya contaban con estructura militar, además de que tenían fuerte arraigo entre sectores urbanos y campesinos. La guerrilla se convirtió en una verdadera alternativa de poder y [...] a mediados de 1982 ya controlaba amplias zonas en el norte y en el noroeste del país. (Fonseca, 1998, p. 268)
\end{abstract}

Los sectores más conservadores por su parte, también se organizan en dos agrupaciones: la Democracia Cristiana y el partido Alianza Republicana Nacionalista (ARENA). Este último, asesorado por el gobierno de los Estados Unidos entrena grupos paramilitares conformados en "Escuadrones de la muerte", que con el fin de combatir la guerrilla e impedir el avance del comunismo persiguen, secuestran, torturan, desaparecen y asesinan a una gran cantidad de personas. Se dice que era frecuente ver cadáveres a orillas de las carreteras y en los barrios citadinos o periféricos. Se ha llegado a estimar en setenta y cinco mil los muertos y entre veinte mil y cuarenta mil los desaparecidos (cfr. Proner, 2012). ${ }^{10}$ Todos estos hechos, agravados aún más por una severa crisis económica, ocasionan incertidumbre, miedo y desesperanza que incitan a cientos de miles de personas a huir del país, impulsando fuertes movimientos migratorios. ${ }^{11}$

Todavía en 1990 el Representante Especial de la ONU, en su informe anual sobre la situación de los derechos humanos en El Salvador, expresa su preocupación y la de la Comisión de Derechos Humanos, "por la alarmante frecuencia con que miembros de la Defensa Civil del país, se ven involucrados en graves hechos de sangre, robos, asaltos, violaciones y abusos de autoridad, creando un estado permanente de terror e inseguridad en la ciudadanía" (Comisión de la verdad, s.f., p. 57).

La incidencia de estos sucesos en la literatura salvadoreña es clara, pues aún se viven sus secuelas. Como afirma Nadine Haas (2009, p. 4): "tanto la sociedad como la cultura no sólo fracasan ante la violencia, sino que además ellas mismas la engendran. Una sociedad que se reduce a unos pocos y que reserva para estos la cultura, violenta a los muchos a los que excluye". Según esta autora: "La violencia política de las décadas anteriores fue relevada por la violencia posconflicto o posguerra. Si hablamos de la violencia posconflicto en Guatemala y El Salvador, hablamos en primer lugar de delincuencia o violencia criminal, del crimen organizado, de las maras, de femicidios, etc."12 (Haas, 2009, p. 7).

En sus amplios estudios sobre la literatura centroamericana y la salvadoreña en específico, la crítica Beatriz Cortez $(2010)^{13}$ ha acuñado el título de "literatura de posguerra" para referirse a ella, así como "estética del cinismo" para explicar el desencanto y desesperanza que se percibe en los textos producidos en esta zona del mundo en la época actual, donde la violencia aún pervive, como indica Haas. 
De acuerdo con lo dicho, en esta lectura se propone que la sociedad plasmada en los dos cuentos es una parodia ${ }^{14}$ del discurso que la historia oficial ha instituido sobre la sociedad salvadoreña de los últimos treinta años, donde aparentemente se han cumplido todos los requisitos de un Estado de derecho. 15 Pero este es una "ficción", un "simulacro", ya que los asesinatos, las desapariciones y muchos otros delitos contra la vida y la seguridad de las personas se llevaron a cabo bajo el amparo de los grupos en el poder, los cuales los han ocultado, invisibilizándolos e impidiendo su mención. Esto ha dado como resultado que los muertos se mantengan presentes en la memoria colectiva. ${ }^{16}$ Así es entendible que en los cuentos de Hernández la muerte violenta sea considerada normal y no cause reacción en los personajes, quienes no expresan asombro, dolor, ni miedo ante ella. Actúan como si esos hechos no existieran, tal y como los grupos hegemónicos en el poder pretendían.

Desde esas perspectivas, la construcción del ambiente y las situaciones narradas en los cuentos se analizan desde la estética fantástica por medio del discurso paródico, que remite a una realidad concreta, tal y como lo propone Bravo (1988). Igualmente, es posible leerlo desde lo que Linda Hutcheon ha llamado "parodia posmoderna" cuyo uso en la literatura permite que la sociedad sea juzgada de forma irónica, pues realiza: "una especie de "revisión" impugnadora o de relectura del pasado que confirma y subvierte a la vez el poder de las representaciones de la historia" (Hutcheon, 1993, p. 189). En los cuentos de Hernández se revisa la historia oficial, se des-cubren sus estrategias de negación y se nombra lo innombrado, escenificándolo y exponiendo la invisibilización de criminales y crímenes, mientras se recuerda a las miles de víctimas anónimas, provocando una necesaria reflexión sobre lo sucedido y denunciando la impunidad de los culpables. Según Hutcheon (1993, p. 194): "La parodia puede ser empleada como una técnica autorreflexiva que llama la atención hacia el arte como arte, pero también hacia el arte como fenómeno ineludiblemente ligado a su pasado estético e incluso social”. Es el enfoque que doy a mi lectura de los relatos de Hernández, como se verá a continuación.

\section{La crítica sobre la obra de Claudia Hernández}

La obra de Claudia Hernández ha recibido varios premios importantes y es cada vez más conocida y estudiada en el seno de la academia, por lo que es posible encontrar actualmente artículos como el de Carla Rodríguez, titulado "Cuerpos desgarrados: textualidades desgarradoras. Una aproximación a la escritura de Claudia Hernández" (2012), en el cual estudia esta obra como parte de una "literatura centroamericana" que no por utópica es menos real o menos valiosa. Rodríguez se apoya -entre otros autores- en algunas propuestas de Beatriz Cortez $(2000)^{17}$ sobre la llamada "estética del cinismo", la cual responde a las premisas del posmodernismo. Estas, señala Rodríguez, llevan hacia "la desesperanza, el individualismo y la indiferencia ante cualquier realidad que no sea la personal" (2012, p. 122), lo cual fundamenta el interés que existe en la actualidad alrededor del cuerpo. El estudio de esta autora, acorde con tales planteamientos, se centra en el cuerpo como exponente performativo de los discursos culturales. En los cuentos analizados, "Abuelo", "Manual del hijo muerto" y "Mediodía de fronteras" el cuerpo de los protagonistas es el lugar donde se inscribe la violencia. En ellos se expone la fragmentación del sujeto y se muestra el suicidio como "una realidad inminente". Se alude, además, a una problemática que Hernández ha vivido en carne propia y trabaja ampliamente en varios relatos: la experiencia de la inmigración. 
Otro artículo académico que aborda los cuentos que analizo en este estudio es "Hechos de un buen ciudadano de Claudia Hernández. La naturalización de 'lo fantástico"” (2014), de José Pablo Rojas, quien parte de "la naturalización de lo extra-ordinario" para afirmar que dicha naturalización intensifica "la ambigüedad del texto en relación con la realidad misma: estabilizar el dominio de lo aparentemente imposible, no es sino poner en entredicho la doxa; es decir, todo conocimiento de uno o del mundo que se entienda como normal" (2014, p. 50). Para realizar su análisis, Rojas se fundamenta en los aportes sobre "Lo siniestro" de Sigmund Freud y en los de la crítica Ana Markovic $(2008)^{18}$ y plantea que los cuentos que analiza pertenecen al fantástico moderno, en el cual se presenta un hecho sobrenatural que es aceptado como normal por los personajes desde el principio del cuento, sorprendiendo a los lectores.

Una investigación extensa que estudia el conjunto de la obra de la autora salvadoreña, es la tesis de doctorado Subalternidad, Exclusión y Violencia: La construcción de subjetividades en la obra literaria de Claudia Hernández (2013) de Hilda Gairaud. Esta autora ubica la obra escogida en la literatura de posguerra y desde esa perspectiva destaca varios ejes de análisis, a saber: la violencia, el cinismo, la fragmentación y la migración. También estudia varios temas y estrategias literarias que considera importantes en la obra de Hernández como son la condición subalterna, lo abyecto y el realismo grotesco, entre algunos otros.

Señala además, que algunos críticos ${ }^{19}$ han clasificado esta obra en lo "real maravilloso", en el "realismo mágico" e inclusive en lo "fantástico". ${ }^{20}$ Reconoce que muchos de los relatos son ubicables en esos contextos ya que "combinan elementos reales con fantásticos que revelan esas realidades imposibles de describir siguiendo la mímesis y entonces se remiten al ámbito simbólico" (Gairaud, 2013, p. 69). Sin embargo, no las desarrolla a profundidad al considerar que los textos de Hernández van más allá de la magia y la fantasía. No obstante, en mi lectura del texto desde las perspectivas teóricas utilizadas es posible descubrir una realidad ocultada, que es expuesta y denunciada por medio de la estética fantástica, demostrándose que esta última no es una práctica textual "escapista" y alejada del contexto en que se produce, como se verá a continuación.

\section{4. "Hechos de un buen ciudadano I"}

Desde el título, en "Hechos de un buen ciudadano I" se anuncia, escuetamente, que en el texto se hablará de las obras de un buen ciudadano. Al indagar el exacto significado de la palabra ciudadano, entre varias acepciones que da el DRAE, se dice que es una "persona considerada como miembro activo de un Estado, titular de derechos políticos y sometido a sus leyes". ${ }^{21}$ Algunos de esos derechos, establecidos desde 1789 y reconocidos ahora en la mayor parte del planeta, son el derecho a la libertad, a la seguridad, a la propiedad y la resistencia a la opresión. ${ }^{22}$ Aunque habría que considerar como primer derecho fundamental de todos los seres humanos -no sólo de quienes sean ciudadanos y ciudadanas- el derecho a la vida. ${ }^{23}$ Otra de las acepciones de ciudadano lo señala como un "hombre bueno", ${ }^{24}$ un hombre ${ }^{25}$ bondadoso. Por lo tanto, en los relatos se conocerán hechos que permitirían adjudicarle esos calificativos a un hombre que cumple con las leyes de su país y que además, es bueno.

El cuento, de estructura lineal, comienza in medias res y un narrador/protagonista anónimo cuenta la historia. Habla en primera persona y desde su punto de vista, por medio de un discurso confesional, centrándose en él mismo y sus intereses al exponer los hechos. Se refiere desde el primer párrafo a sucesos ocurridos en el pasado, los cuales introducen inmediatamente a las personas lectoras ante lo que se podría llamar un hecho "a-normal": 
Había un cadáver cuando llegué. En la cocina, De mujer. Lacerado. Y estaba fresco: aún era mineral el olor de la sangre que le quedaba. El rostro me era desconocido, pero el cuerpo me recordaba el de mi madre por las rodillas huesudas y tan sobresalientes como si no le pertenecieran [...] (Hernández, 2007, p. 17)26

La lacónica descripción del cadáver indica, sin lugar a dudas, que esa muerte no se produjo por accidente y la joven fue torturada, dadas las laceraciones que presenta. Se trata por lo tanto de un homicidio, hecho que muestra según los patólogos forenses españoles José Manuel Tortosa y Santiago Crespo, la existencia de "[...] voluntad y actuación de terceras personas de que se produzca esa muerte" (2011, p. 100).

El hallazgo también sugiere -o quien lee rápidamente lo asume- que podría existir mala intención en el acto de depositarlo en la cocina del narrador, a quien tal vez se estaría intentando inculpar por el crimen. En ese sentido, el cuento pareciera derivar hacia lo policíaco cuando el hablante continúa explicando: "Ninguna de las cerraduras había sido forzada. Tampoco había un arma por ningún sitio. Nada había que me diera pistas sobre el asesino, que había limpiado hasta las manchas de sangre en el piso. Ni una sola gota dejó” (p. 17).

El suceso deja en evidencia la inseguridad existente dentro de la casa, puesto que un asesino ha entrado sin forzar cerraduras y se marcha sin dejar huellas, convirtiendo un lugar íntimo y acogedor -símbolo del ser interior, recuerdo del vientre materno e imagen del universo, ${ }^{27}$ según Chevalier (1995, pp. 257-259)- en una casa siniestra, ${ }^{28}$ donde cualquiera puede introducirse a depositar un cadáver desnudo y partir sin mayores contratiempos.

Dado que el narrador no se ha identificado y permanece anónimo hasta el final, su confesión sobre los muchos asesinados vistos podría creerse producto del tipo de profesión que desempeña - ¿será oficial del ejército, policía, médico, investigador, guerrillero?, ¿trabajará en una morgue, será sepulturero?-. Pero el hombre tampoco cuenta nada sobre él, excepto -como se ha dicho- lo que pudiera convenir a sus fines. De manera que hasta este momento, no es posible saber por qué ha visto tantas personas asesinadas. El narrador no se inquieta por averiguar sobre el posible culpable del hecho, las motivaciones del crimen o las razones para dejar ese cuerpo en su casa. No habla, en ningún momento, de dar cuenta a la policía u otro organismo, que pudiera hacerse cargo de las pesquisas y sentara las responsabilidades correspondientes, como se haría en cualquier Estado de derecho, tal y como explican Tortosa y Crespo:

\footnotetext{
[...] lo que subyace en toda muerte violenta es la existencia de una posible responsabilidad en la producción de esta muerte. La muerte violenta debe ser investigada de forma minuciosa para ofrecer el máximo de datos a la administración de la Justicia. [...] (para) establecer las diferentes responsabilidades que pueda haber (Tortosa y Crespo, 2011, p. 99)
}

El lenguaje utilizado por este protagonista es coloquial y sus descripciones realistas. Su actuación, desde un principio parece ser la "correcta", aunque el tono, nada sentimental ni tierno que utiliza al comparar las rodillas de la joven con las de su propia madre, contribuye a la creación de una atmósfera ficticia, hiperreal. Es un tono ligero y hasta podría pensarse que burlón o humorístico, cuando agrega sobre la joven asesinada que: “[...] tenía cara de llamarse Lívida, tal vez por el guiño de lamento que se le había quedado atascado en los labios amoratados" (p. 17), dejando patente una visión determinista sobre dicho nombre -que acompañará al cadáver a lo largo de los dos relatos- con el cual se describiría el aspecto "normal" de cualquier persona muerta, pues lívida es un adjetivo que significa "amoratado" o "intensamente pálido". ${ }^{29}$ 
A partir del tercer párrafo del relato -cuya extensión es de apenas tres páginas- se evidencia su narcisismo en el interés mostrado por el hombre por exhibirse como alguien con iniciativa, que enfrenta eficientemente los sucesos que lo afectan mejor que cualquiera:

\footnotetext{
Como cualquier buen ciudadano habría hecho, no esperé a que apareciera mensaje alguno en la radio o en la televisión, sino que hice imprimir uno en el periódico que decía: Busco dueño de cadáver de muchacha joven de carnes rollizas, rodillas saltonas y cara de llamarse Lívida. Fue abandonada en mi cocina, muy cerca de la refrigeradora, herida y casi vacía de sangre. Información al 271-0122. (p. 17)
}

La información incluida en el anuncio, tan poco precisa que imposibilitaría cualquiera identificación de la muerta, además de los detalles que incluye, inducen a cuestionar la salud mental del narrador, quien publicita de un modo tan imprudente un hecho que -se asumepodría acarrearle una posible acusación por un crimen que, según él, no cometió, todo lo cual refuerza la atmósfera singular percibida desde el inicio.

Como resultado de la publicación, el protagonista recibe cuatro llamadas. La primera es de un hombre de voz aguda, quien busca el cadáver fresco de un miembro de su familia que fue asesinado. Desean enterrarlo para "poder vivir sin cargos de conciencia" (p. 18). Surge la pregunta sobre la certeza de esa familia respecto al posible crimen, ¿cómo saben que su pariente desaparecido fue asesinado si no lo han encontrado? Quien lee empieza a preguntarse sobre el tipo de sociedad en que suceden los hechos. ¿Será que la norma fijada por la costumbre es asumir que si alguien desaparece, ha sido asesinado? Esto no lo explica el hablante, pero el hecho establece una continuidad con la primera muerta. El narrador promete llamar al hombre si por "casualidad" le apareciera un cadáver masculino en su casa, "aunque no fuera junto a la refrigeradora" (p. 18). Considerar una "casualidad" la aparición de cadáveres dentro de las casas de habitación llama la atención de nuevo hacia lo absurdo y siniestro del hecho y muestra la poca transparencia del lenguaje, el cual en la literatura fantástica contemporánea se vuelve oscuro, torpe, indirecto, según afirma Roas (2001).

La segunda llamada proviene de una mujer, trabajadora en una oficina pública según adivina el narrador, ya que ella no quiere identificarse. Sólo desea felicitarlo por su anuncio porque "Ya no hay ciudadanos como usted" (p. 18). Esta llamada permite pensar que en el "ahora" textual nadie se involucra de esa manera cuando aparece un cadáver en su casa. Seguramente prefieren disponer de él de modo discreto, sin anunciarlo, porque lo cierto es que no podrían ignorarlo.

La tercera llamada la hace un funcionario público para preguntarle si cumplió los procedimientos de salubridad indicados para evitar contagios en su lugar de residencia. Promete enviarle un formulario donde el narrador se haría responsable en caso de que se diera "una epidemia de muertos en los alrededores" (p. 18). Se conoce así que la aparición de cadáveres dentro de las casas y en los alrededores de los barrios es cuantiosa y frecuente. Parecen ser tantos los cuerpos que para enfrentar la situación quienes tienen el mando ordenan la implementación de procedimientos y la aplicación de formularios burocráticos, tal vez para justificarse y mostrar haber hecho algo al respecto, sin importar lo absurdo de la medida. Todo indica, además, que el formulario mencionado delega la responsabilidad -¿de la acción?, ¿del cadáver?- en quien lo ha encontrado y no en quienes perpetraron el crimen.

La última llamada es hecha por un matrimonio de edad avanzada que pregunta por su hija, de nombre Lívida, desaparecida y con características similares a las del anuncio. Pero ellos creen a su hija con vida. El narrador confiesa sentirse conmovido y por eso no insiste en convencerlos de que la joven en su casa es, posiblemente, la Lívida que ellos buscan. Como 
sucede con la primera llamada, otra persona es buscada por sus familiares. Muestra clara y recurrente de las desapariciones y muertes violentas en la ciudad del relato, lo cual podría explicar por qué el narrador asegura haber visto tantos asesinados.

Esas llamadas rompen la propia representación y experiencia de la realidad cotidiana de quienes vienen leyendo el cuento y los obliga a confrontarla con esa realidad "otra", extraña y amenazante que es la realidad de los personajes. La extrañeza y ambigüedad que se ha producido introduce de lleno el relato en la estética fantástica, pues como señala Roas (2001, p. 26): "sabemos que un texto es fantástico por su relación (conflictiva) con la realidad empírica", la cual, como se ve en este cuento, es transgredida.

A lo anterior habría que agregar, de nuevo, el modo casual y el tono superficial con que el narrador habla de tales llamadas, aun cuando confiesa sentirse "conmovido". Todo esto evidencia la cotidianeidad de los sucesos, su "normalidad". Porque ninguno de los personajes -contados desde la visión del narrador- los rechaza, ni los califica de horrorosos. Nadie menciona a los criminales, ni se refiere al crimen llamándolo por su nombre. Tampoco parecen asombrados, extrañados, o asustados, como debería ser el caso, ya que como explica Chevalier es común que: “[...] el misterio de la muerte se afronte [...] con angustia y se figure con rasgos pavorosos. Semejante actitud entraña más la resistencia al cambio y a una forma de existencia desconocida, que no el temor a una reabsorción en la nada" (1995, p. 731). Pero nada de esto aparece plasmado en lo narrado.

Es por todo lo dicho que propongo esta realidad textual como parodia de esa otra realidad monstruosa, que también "normalizó" a los muertos y desaparecidos, convirtiéndose en una hiperrealidad, una realidad construida, más "real" que la realidad y por lo tanto ficticia (Baudrillard, 2007), donde la ley, el orden y la justicia son también simulados. Los procedimientos establecidos en el texto para lidiar con los sucesos narrados son fantásticos por absurdos e hiperbólicos. Según afirma Bravo, una vez establecido el hecho fantástico, el cual vendría a ser la aparición del cadáver dentro de la casa, así como la ausencia de reacciones por parte de los personajes y las actividades realizadas para enfrentar los hechos, el absurdo surge, puesto que el hecho es asumido desde la perspectiva de las consecuencias, "intentando adecuar el hecho invasor y extraño, en un contexto que insistentemente lo rechaza por contraste" (Bravo, 1988, p. 43). Conforme avanza la historia y acorde con ella, las absurdas acciones del narrador se evidencian cada vez más como la parodia de una conducta virtuosa, lo cual lo transforma a él en un simulacro, ${ }^{30}$ que habita en una ciudad cuya realidad también es ficticia, artificial.

El absurdo aumenta cuando el hablante cuenta cómo debe enfrentar, él sólo, la situación, pues pasan ocho días sin que nadie reclame el cadáver y ya "comenzaba a oler mal pese a mis cuidados y a mis baños con bálsamo y sal de cocina” (p. 19). Tal comentario establece su conocimiento de las técnicas elementales de embalsamamiento y conservación de cadáveres, sin recurrir a la refrigeración, de modo que no pareciera descabellado pensar que este hombre ha estado muy en contacto con los muertos, sea porque se encarga de producirlos o de prepararlos para ser dejados en cualquier sitio, o con otros fines no manifestados por él, de ahí los muchos asesinados que dice haber visto y el tono admirativo que utiliza cuando se refiere al cadáver de "Lívida": "He visto muchos asesinados en mi vida, pero nunca uno con un trabajo tan impecable como el que le habían practicado a la muchacha [...]" (p. 17).

Por otro lado, el uso de la sal de cocina es siniestro e irrisorio al mismo tiempo. Aunque ciertos tipos de sales y otros elementos químicos se utilizan en la conservación de los cuerpos, el hombre da la impresión de estar conservando el cadáver en "salmuera" -como si 
se tratara de algún tipo de alimento- lo cual termina de afirmar la imagen macabra y grotesca con que se presenta el cuerpo.

Para resolver la situación en que se encuentra, el narrador ofrece el cuerpo de "Lívida" al hombre de la voz aguda que lo llamó de primero, sugiriéndole que lo haga pasar por el de su pariente desaparecido, para sepultarlo y darle tranquilidad a la familia. El hombre acepta agradecido y acude con un ataúd. Introducen el cadáver junto con una serie de objetos, que servirán para simular el peso de un hombre y lo sellan. El de la voz aguda pide discreción y el narrador se la promete.

La actuación del narrador/protagonista es construida desde su propio discurso como ejemplar y digna de reconocimiento. La mujer que efectúa la segunda llamada lo aprecia en ese sentido y él, desde una posición narcisista de su propia valía lo acepta, construyéndose, a continuación, de esa manera, porque además conviene a sus intereses. Como explica Freud (1980), los narcisistas dirigen la libido hacia ellos mismos y se convierten en personas vanidosas, egocéntricas, que en realidad tienen una baja autoestima, por lo cual necesitan compararse constantemente con los demás y para destacarse construyen una imagen artificialmente sobrevalorada de ellos mismos. Por medio de ella elevan de modo exagerado su propia importancia, la cual viene a justificar sus exigencias y caprichos. Necesitan de la admiración y adulación constantes, al mismo tiempo que manifiestan gran egoísmo y desconsideración hacia las necesidades y sentimientos de las demás personas (Freud, 1980), como pareciera ser el caso del narrador.

En esta primera parte, podría decirse que este hombre ha tenido éxito en establecer una imagen suya que guarda fidelidad a su posible ser de "hombre bueno". A pesar de esto, habría que prestar atención a su conducta en relación con la pareja mayor que busca a su hija desaparecida. El hablante confiesa no querer hacerlos sufrir, por lo cual rechaza la posibilidad de entregarles el cadáver de "su" Lívida, que muy bien podría ser la Lívida que ellos buscan. Al hacerlo, se asigna el derecho de decidir por la pareja de ancianos. ¿Será mejor no conocer el paradero de la joven a saberla muerta? ¿Será más beneficiosa la incertidumbre que la certeza, aunque se trate de un hecho tan doloroso? A estos padres no se les permite decidir, en nombre de una compasión que dice sentir el narrador, quien a pesar de su justificación, actúa de modo conveniente para sus propios fines: el deseo de reconocimiento, admiración y respeto por "sus hechos".

Entre tales hechos habría que incluir, por cierto, la mentira y la simulación, al hacer pasar el cuerpo de Lívida por el de un hombre, agregando peso al ataúd para salir airoso con el engaño, además de prometer discreción al hombre de la voz aguda, para luego contar lo sucedido y resaltar su propia figura y actuación.

En el siguiente relato, el protagonista sigue procurando su propio beneficio y el simulacro de su persona se impone sin lugar a dudas.

\section{5. "Hechos de un buen ciudadano II"}

En este segundo cuento, la manifestación del absurdo, la parodia, lo siniestro y también un humor macabro se agudizan y marcan una transformación irreversible en la percepción que se venía estableciendo de ese "buen ciudadano". El clímax y conclusión de la historia se dan en esta secuencia -también de unas tres páginas de extensión- donde el narrador, ya conocido en su ciudad por su actuación anterior, recibe numerosas llamadas por medio de las cuales se solicita su ayuda sobre la mejor manera de disponer de los cadáveres, 
que continúan apareciendo en las casas de habitación: "en las entradas, en los dormitorios, en los pasillos" (p. 39). El hombre se presta con gusto y veinte personas junto con los cadáveres encontrados en sus residencias, llegan a su casa.

Manteniendo el tono de la narración, el protagonista comenta frívolamente que como "su” Lívida, los demás cuerpos aparecieron desnudos. Sin embargo, los dueños de las casas, por su nerviosismo y "para no levantar sospechas al transportarlos" hasta la del narrador, los vistieron apresuradamente con lo primero que encontraron a mano, de modo que "había muertas con ropas de hombre, niños con faldas floreadas, jóvenes con indumentarias de ancianos y viejos embutidos en camisas con motivos infantiles" (p. 39).

En un primer momento, el absurdo de la situación se impone: veinte cadáveres son transportados a la misma casa y en una misma tarde "sin levantar sospechas", a pesar de ir vestidos "como locos". El temor a las sospechas no es aclarado en la narración, aunque quien lee concluye que evitan ser descubiertos por algún tipo de autoridad no identificada. Pero inmediatamente después la escalofriante realidad textual expone la violencia desmedida imperante, al tratarse de "veinte cadáveres de ambos sexos, de todas las edades y de diferentes partes de la ciudad" (p. 39).

La ciudad plasmada en el relato se muestra como un sitio brutal en el que no se respeta a nadie, ya que hay cuerpos de ancianos, de hombres y mujeres, de jóvenes y niños, víctimas todas del horror y del desprecio, pues para privarlos de la vida, los despojaron hasta de sus ropas, arrojándolos luego en las casas de personas desconocidas. Explica Chevalier que en

\footnotetext{
la tradición bíblica la desnudez puede tomarse en principio como símbolo de un estado donde todo está manifestado y no velado. [...] muy naturalmente la desnudez designa también la pobreza y la debilidad espiritual y moral. [...] El simbolismo es a veces netamente peyorativo: la desnudez es la vergüenza (Chevalier, 1995, p. 412)
}

En relación con el primer significado simbólico, la desnudez de esos cuerpos manifiesta, ciertamente, la ausencia de vida. La impotencia frente al poder y la ausencia de una posible defensa experimentada por los habitantes de esa ciudad, quienes sufren la brutalidad de los asesinos -cuya ausencia en el texto impone siniestramente su presencia en virtud de los cadáveres y desaparecidos- podrían considerarse una muestra de pobreza y debilidad por parte de aquellos. La vergüenza señalada por Chevalier, se materializa aún más al ser vestidos de modo grotesco, como si fueran a participar en un desfile de carnaval. ${ }^{31}$ Toda esa descripción, a pesar del tono frívolo y algo humorístico del narrador cuando refiere los sucesos no causa risa, pues se trata de un humor macabro que desnuda el supuesto orden de una realidad distorsionada. En ese sentido señala Roas que:

\footnotetext{
[...] la combinación de lo fantástico con la ironía y/o la parodia potencia el efecto distorsionador del relato, sin que, por ello, los fenómenos narrados pierdan su condición de imposibles, puesto que tales recursos nunca se imponen al objetivo central de lo fantástico: transgredir las convicciones sobre lo real del lector, proyectadas en la ficción del texto y, con ello, provocar su inquietud (Roas, 2011, p. 174)
}

Una vez reunido con los dueños de casa y los cadáveres, el narrador enseña a los primeros el procedimiento para salar los segundos. También les explica la manera de llenar los formularios de la oficina de salubridad -él mismo llama por teléfono- y, muy amable y cortés -según su autopercepción narcisista ya comentada- les muestra cómo elaborar el anuncio para el periódico y los acompaña a publicarlo, como lo haría todo "buen ciudadano". En agradecimiento por su ayuda los dueños de las casas desean darle dinero 
pero él no lo acepta. Los visitantes insisten y al final depositan ese dinero en cajas selladas que dejan en la sala de su casa, lo cual más adelante resulta de interés para exponer la verdadera naturaleza del narrador.

Realizados los trámites referidos, todos juntos se sientan a esperar las llamadas de los posibles familiares. Afirma el narrador que la "espera fue agradable", comentario bastante inquietante en vista de que en esa casa hay veinte cadáveres salados, rodeados de una serie de circunstancias extraordinarias.

El actuar de los personajes parece extraño, pues mientras esperan no guardan el respeto obligado en una ocasión de esa índole, sino todo lo contrario. Celebran su reunión alegremente y como si estuvieran en una fiesta toman bebidas y comparten bocadillos. La descripción del narrador así lo enfatiza: "La pasamos muy bien. Intercambiamos historias, algunos obsequios, ánimos y, por supuesto, alegrías cuando comenzamos a recibir las llamadas de los familiares de los cadáveres" (p.40). Los sentimientos, de agrado y satisfacción ante la experiencia que están viviendo, ocultan y callan la violencia y sus consecuencias: innumerables muertos y desaparecidos, violación del derecho a la seguridad personal, a la propiedad privada, además de los esperables sentimientos de miedo, incertidumbre y horror. Sin lugar a dudas, lo siniestro circula en el texto y así lo perciben lectoras y lectores. Tal percepción se acrecienta ante la reacción de los parientes que reclaman los cuerpos, cuando aseguran que sus muertos nunca fueron mejor tratados, reafirmando el clima social de violencia existente:

De todas partes de la ciudad y hasta de fuera de ella aparecían parientes emocionados que nos agradecían con lágrimas por el buen trato que habíamos dado a sus muertos (algunos dijeron incluso que ni en vida habían sido tan bien cuidados sus hijos, hermanos, esposas, padres o amigas) (pp. 40-41)

Cuando ya se han entregado trece cadáveres, los visitantes se desbandan. El narrador ofrece cuidar los siete restantes, por lo cual es reconocido de nuevo: "En verdad es usted un buen ciudadano" (p. 41). Una vez queda solo con los cadáveres, el desenlace llega rápidamente.

El hombre lava los cuerpos para eliminar el exceso de sal, tarea que le toma tres días. A esas alturas, dichos restos humanos estarían en un acelerado proceso de descomposición que además de lástima sólo podrían provocar rechazo y asco, pero el hablante no da detalles, mientras sigue contando en tono ligero y sin ningún énfasis lo que sucede. Aunque es evidente que sabe lo que hará, se preocupa por mantener -ante los ojos de la ciudad- su simulacro de buen ciudadano, por eso procede a cortar los cuerpos con cuidado: "Para que no fueran a crujir demasiado los huesos y llamaran la atención de los vecinos. Después herví los trozos, deshilé la carne y la mezclé con una salsa hecha con los tomates que cultivo en mi jardín. El sabor era inmejorable: Estaba yo seguro de que gustaría" (p. 41). Con la certeza de esto, el hombre lleva su guiso a "Los sitios que albergan pordioseros, indigentes y ancianos y les serví abundantes porciones las veces que desearon" (p. 41).

Los componentes de la salsa y la receta empleada resultan en un guiso de estupendo sabor, que el narrador aprueba con deleite, descubriéndose ante los ojos de quien lee -desde su propia confesión- como un caníbal, un monstruo carente de escrúpulos, que probablemente ha visto tantos asesinados porque los recoge de las calles, o -simulando bondad- de las casas de otras personas, con el pretexto de "cuidarlos" y brindarles el tratamiento anteriormente narrado, para luego alimentarse de ellos, engulléndolos con satisfacción. Como afirma Celina Manzoni (2000) al analizar "El antropófago", cuento de Pablo Palacio: ${ }^{32}$ 
Los relatos sobre antropófagos suelen ubicar a ese otro que se alimenta de carne humana en otro tiempo o en otro espacio, pero también puede suceder [...] que la escritura recupere el miedo ante la inmediatez del peligro o que desplace el sentido ritual del acto por la perspectiva gastronómica (Manzoni, 2000, p. 450)

que es lo que sucede en este relato de Hernández.

Ante quien lee, el hombre no manifiesta vergüenza por su conducta, aún a sabiendas de que ha violado los códigos legales, éticos, morales, sanitarios y religiosos establecidos en la gran mayoría de las sociedades, donde se prohibe la ingesta y el tráfico de carne humana. Tiene plena conciencia de lo realizado e inclusive se jacta de ello, exhibiéndose como un ser cruel y perverso. La naturalidad con que ha simulado ser un "buen ciudadano" es siniestra, horrorosa y de un oportunismo retorcido, que le incita a sacar provecho de los cuerpos encontrados para utilizarlos como ingrediente principal en su macabro platillo, explicándose, ahora sí, su amplio conocimiento de los muchos asesinados, cuyos cuerpos fragmentados han sido desechados (Manzoni, 2000, p. 451). Su reacción ante la aparición de Lívida podría explicarse, entonces, en función de su temor a que fuera una trampa para exponer su comportamiento a-normal y por eso la publicita tan insensatamente. De paso, se aprovecha de la situación de un modo que fortalece su narcisismo para lograr admiración y reconocimiento, pues como afirma Foucault (2011, p. 94): “el criminal siempre es un pequeño déspota que hace valer su despotismo y en su propio nivel, su interés personal".

Las personas que degustaron su receta -también desechos vivientes de la sociedad-al saborear tan deliciosa y abundante comida ofrecida con una mentida generosidad, desconocen haber participado en una especie de parodia de la ceremonia cristiana de la comunión, donde los fieles se comen, simbólicamente, el cuerpo de Cristo sacrificado. O en una actualización de las ceremonias realizadas en épocas lejanas por los aztecas, cuando gracias a "las guerras floridas" obtenían prisioneros para ser muertos y comidos como parte de sus rituales sagrados en honor a sus dioses. En estos cuentos de Hernández todos los cadáveres son producto del sacrificio, pero más aún los que no fueron reclamados por sus familiares. El único beneficiario de toda esta historia pareciera ser el narrador/protagonista, el antropófago.

Este hombre demuestra una enorme satisfacción por el engaño realizado a toda una ciudad, a partir del abuso de seres que no podían defenderse, por ser desechos sin vida convertidos en carne, unos y desechos vivientes convertidos en caníbales involuntarios, los otros. Ninguno de ellos le importa al narrador, quien reconoce con desparpajo haber mentido, cuando para guardar las apariencias ante sus conciudadanos, les asegura que la carne del guiso la pudo adquirir con el dinero depositado en las cajas selladas.

Se descubre como caníbal, ${ }^{33}$ desde dos de los significados que le adjudica el DRAE a esta palabra: es antropófago y también cruel y feroz al utilizar abusiva y despiadadamente la desgracia de los demás para lucrar en su propio beneficio. Su ferocidad es encubierta bajo el manto de la simulación. Visto así, el narrador ciertamente es un personaje monstruoso, ${ }^{34}$ cuya conducta rompe con el orden natural desde la apariencia psicológica de lo considerado "normal", dado que su transgresión es de orden social, moral y legal.

Todo esto permite que el sentimiento de lo siniestro se mantenga hasta el mismo final e incita a reflexionar sobre la maldad presente en lo sucedido (Bravo, 1998). ¿Cómo saber cuándo el monstruo se encuentra oculto entre nosotros, disfrazado de "buen ciudadano"? No es posible exponerlo ante una sociedad que ha silenciado -por motivos no dichos- hechos tan terribles como los narrados en los relatos y que a fin de cuentas podría merecerlo como conciudadano: este hombre es sólo un monstruo más viviendo en una sociedad monstruosa, ya que como indica Foucault: “¿quién no podrá autorizarse a infringir las leyes, cuando el soberano, que 
debe esgrimirlas y aplicarlas, se atribuye la posibilidad de tergiversarlas, suspenderlas o, como mínimo, no aplicarlas a sí mismo? Por consiguiente, cuanto más despótico sea el poder, más numerosos serán los criminales" (2011, pp. 94-95). Por eso el hombre cuenta con orgullo:

\footnotetext{
La ciudad entera lo supo y me aplaudió en un acto público en el que fui llamado hombre bueno y ciudadano meritísimo. Yo acepté el homenaje con humildad y expliqué entonces que no eran necesarias tantas atenciones para conmigo, que yo era un hombre como todos y que sólo había hecho lo que cualquiera -de verdad, cualquiera- habría hecho. (p. 42)
}

Lo anterior permite suponer que los criminales que han torturado, desaparecido y asesinado a todos esas personas también pudieron recibir en algún momento, reconocimientos y consideraciones de respeto por acciones simuladas, parecidas a las del protagonista. De ahí que este confiese ser un "hombre como todos", que ha hecho "lo que cualquiera habría hecho", aunque tenga la certeza de que él es mejor, pues ha triunfado en su engaño.

La burla y la ironía en el tono de su confesión demuestran la idea que tiene de su propia inteligencia, cuando se llama humilde e hipócritamente rechaza merecer tantas atenciones, conseguidas mediante la manipulación y la mentira. Su confesión después de todo resulta bastante coherente si se sigue la lógica de la parodia y del simulacro establecida, al ser habitante de un sitio como el del relato.

\section{Comentarios finales}

De acuerdo con lo analizado en estos dos cuentos, la conducta del narrador/protagonista pareciera cambiar conforme avanza la narración, pero esto es sólo un efecto producido por su propia caracterización de hombre bondadoso y compasivo, ejemplo para sus semejantes, que cumple estrictamente con los códigos de conducta y moral instituidos socialmente. Esta caracterización es fundamental en función de su historia, por la forma en que se presenta y explica su conducta, contando -como se dijo- sólo lo que le conviene y le beneficia. A lo largo de todo el primer cuento y primera mitad del segundo no se aprecia mala intención ni maldad en su conducta. La simulación pareciera motivada por sus buenos sentimientos y gran sensibilidad, al ser alguien que desea destacarse por sus buenos actos. Sin embargo, al final se descubre que su conducta ha sido constante, pues es desde el principio el mismo personaje que se descubre -a sí mismo- al final.

El desenlace, resuelto en los últimos tres párrafos del segundo relato es, por lo dicho, totalmente inesperado, cuando el narrador confiesa el modo en que aprovecha los cadáveres en el delicioso platillo que da de comer a los necesitados, jactándose de parecer generoso. Este hombre simula, engaña, miente y falsea e induce a otros a hacerlo, todo en aras de ocultar su verdadero ser monstruoso y pasar ante los demás como un buen hombre. Al no ser descubierto por sus conciudadanos su confesión no es más que una burla, en la que enseña al público lector su inteligencia y su capacidad para manipular los "hechos". Estos últimos quedan en la impunidad, lo cual le permite triunfar siendo el simulacro de un "hombre bueno y ciudadano meritísimo" (p. 42), digno habitante de un Estado de derecho que no lo es, donde "cualquiera -de verdad, cualquiera- habría hecho" (p. 42), lo que él hizo.

En ese aspecto, la violenta ciudad plasmada en los textos es -como se propuso- una parodia por medio de la cual se expone la falsedad de un constructo histórico e ideológico, establecido en la historia oficial como un Estado de derecho, donde los que detentan el poder acosan, persiguen, torturan, desaparecen y asesinan, a quienes pudieran representar un peligro 
para sus intereses. Tal "Estado" en la realidad "real" es sólo una máscara, un simulacro también, que obliga a los habitantes, que para otros efectos actúan de modo "normal", a asumir que las muertes violentas son parte cotidiana de sus vidas. Podría pensarse que la mirada que normaliza esas muertes es una de sobrevivencia, pues si las consideraran como lo que en verdad son, difícilmente podrían enfrentar el día siguiente, al pensar que los próximos en desaparecer o ser asesinados pudieran ser ellos mismos.

Desde esa perspectiva, los relatos de Hernández no nos dejan indiferentes. Se presentan, siguiendo a Jackson (2001), como 'lo oculto' de la cultura, que viene a subvertir el discurso ideológico dominante. Al mostrar las experiencias vividas en las sociedades actuales por medio de la estética fantástica y la utilización de estrategias como la parodia, el absurdo y la simulación, se plantean cuestionamientos y se induce a la reflexión sobre los sucesos escenificados y muestra el modo en que los personajes lidian con una realidad absurda y siniestra. Parece razonable, entonces, coincidir con Roas cuando afirma que: "El problema de lo fantástico es que cuando nos asomamos a través de ese insólito ángulo de visión, lo único que contemplamos es el horror. No hay nada consolador en esa nueva perspectiva de la realidad" (Roas, 2011, p. 156).

\section{Notas}

1. Se utiliza el sentido literal de la palabra de acuerdo al DRAE: "Representar algo, fingiendo o imitando lo que no es".

2. El presente estudio es resultado parcial de la investigación ya finalizada: "Narrativa breve latinoamericana de las dos últimas décadas. Reescritura de lo fantástico en una selección de cuentos de Claudia Hernández y Alberto Chimal”, inscrita en la Vicerrectoría de Investigación con el número 021-B2166. De ella han resultado, también, los artículos "Seres monstruosos y cuerpos fragmentados. Sus representaciones en dos relatos fantásticos de Alberto Chimal". Revista de Filología y Lingüística. 39 (1) del 2013; "Monstruos del pasado. Una lectura de "El tesoro" y "Siete sirenas" de Alberto Chimal". Káñina Revista de Artes y Letras de la Universidad de Costa Rica. 38 (Extraordinario) del 2014 y "Acercamientos y controversias sobre el estudio de la literatura fantástica actual". Revista de Filología y Lingüística. 40 (1) del 2014.

3. Ambos cuentos están incluidos en De fronteras. Guatemala: Editorial Piedra Santa, 2007.

4. En su artículo “Lo 'oculto' de la cultura”, publicado en 1981 con el título de “Afterword: the 'Unseen' of Culture".

5. Llamado por Freud "Umheimlich".

6. Ver mi artículo "De ciudades y pasiones. Un acercamiento a cuatro cuentos latinoamericanos del fin de siglo". Revista de Filología y Lingüística de la Universidad de Costa Rica. 36 (1), 2010.

7. Por Edelberto Torres-Rivas, Héctor Pérez-Brignoli, Elizabeth Fonseca entre otros (as) historiadores(as).

8. Ver entre otras las obras de Claribel Alegría, Roque Dalton y Manlio Argueta, por ejemplo.

9. Titulado: De la Locura a la Esperanza: la guerra de los Doce Años en El Salvador: Reporte de la Comisión de la Verdad para El Salvador. Esa Comisión estuvo conformada por Belisario Betancour, Reinaldo Figueredo Planchart y Thomas Buergenthal y presenta el documento mencionado en 1992.

10. Proner, C. (2012, 02 de abril). Heridas abiertas en El Salvador. Diario digital Contrapunto. http://www. archivoscp.net/2008-2012/

11. Según la CEPAL: "El aumento de la emigración extrarregional se inicia entre 1970 y 1980, donde el número de salvadoreños que se dirige a otros países más que se duplica. En la ronda de censos de 1980 la cantidad de emigrantes es cerca de 29 000; sin embargo el cambio más notorio ocurre en 1990 donde la cantidad de emigrantes sobrepasa las 500 mil personas. Esto demuestra un crecimiento en la magnitud de la emigración que alcanza el 10\% de la población total de El Salvador, lo que es uno de los porcentajes más elevados de Latinoamérica" (Serie Seminarios y Conferencias. º24, s. f.).

12. Los destacados son del texto original. 
13. Entre otros, en su texto Estética del cinismo. Pasión y desencanto en la literatura centroamericana de posguerra. Guatemala: F\&G Editores, 2010.

14. Tal y como entiende Gerard Genette el concepto de "Parodia mínima", la cual considera "la forma más rigurosa de parodia" que: "consiste en retomar literalmente un texto conocido para darle una significación nueva, jugando si hace falta y tanto como sea posible con la palabras" (citado en Rojo, 1995, p. 73).

15. Entendido como aquel que se rige por un sistema de leyes e instituciones fundamentado en una constitución, cuya base jurídica permite el funcionamiento y acciones de autoridades y funcionarios, quienes deben obedecer sus normas.

16. Como en Pedro Páramo (1955), única novela de Juan Rulfo, reconocida como una de las mejores obras de la literatura universal. En ella los muertos dialogan entre sí y con Juan Preciado, el protagonista, quien llega a Comala a reclamarle a su padre, Pedro Páramo, por haberlos abandonado a su madre y a él. La crítica ha señalado que en esta novela se pide cuentas a la historia por los miles de muertos que la Revolución Mexicana provoca, sin lograr los cambios que se pretendían en beneficio de las mayorías empobrecidas y explotadas.

17. Se refiere al artículo "Estética del cinismo: la ficción centroamericana de posguerra". V Congreso Centroamericano de Historia. Universidad de El Salvador, 10-21 de julio de 2000.

18. En su artículo "Lo fantástico y las normas socioculturales". Amoxcalli. (1), 2008.

19. Desde mi lectura, la obra de Hernández no es compatible con las estéticas de lo "real maravilloso" ni del "realismo mágico" con han propuesto algunos estudiosos. Esas clasificaciones han sido utilizadas de manera poco crítica, adjudicándolas de modo esencialista e indiscriminada a la producción literaria de América Latina, sin un estudio profundo de los rasgos que cada obra presenta. Esto ha llegado al punto de confundir ambas estéticas y utilizar sus nombres indistintamente, considerándolas lo mismo. Inclusive cierta crítica ha inscrito la obra de Julio Cortázar y Jorge Luis Borges en el "realismo mágico", ignorando sus rasgos específicos que los identifican claramente como textos fantásticos. Tema que he comentado en artículos anteriores.

20. El estudio realizado por José Pablo Rojas, comentado líneas arriba, profundiza y estudia, específicamente y de modo pertinente lo fantástico en los cuentos mencionados, los cuales son parte del corpus de este trabajo.

21. DRAE. Tercera acepción.

22. Establecidos desde 1789, para los hombres - no para las mujeres- en la Declaración de los derechos del hombre y del ciudadano, documento fundamental de la Revolución Francesa.

23. Instituido en el artículo 3 de la Declaración Universal de los Derechos Humanos.

24. DRAE. Cuarta acepción.

25. Referido exclusivamente a los hombres, aunque la RAE aún lo utiliza como genérico, en el supuesto de que incluye por igual a hombres y mujeres, posición que no comparto pues considero que excluye o inferioriza a las mujeres, como lo expliqué por ejemplo en "Enfrentamientos y rebeliones en un microcosmos urbano: Historias de ascensor". Revista de Lenguas Modernas de la Universidad de Costa Rica. (11), 2009.

26. A partir de esta cita solo se acreditará el número de página. Todas provienen de la edición de la Editorial Piedra Santa, 2007.

27. Desde su simbolismo como "imagen del universo", lo sucedido en la casa es muy siniestro al ser una pequeña muestra de lo que sucede en el mundo exterior.

28. Siguiendo la definición para lo siniestro planteada por Freud (1981).

29. De acuerdo con el DRAE.

30. En el sentido que le atribuye el DRAE en su 3a. acepción: "Ficción, imitación, falsificación". El narrador simula ser algo que nunca ha sido.

31. En La cultura popular en la Edad Media y el Renacimiento (1999), para explicar su concepto del carnaval Bajtín propone una concepción del "mundo al revés", donde por medio de la sátira y la parodia se exponen y critican las contradicciones del mundo real. En el carnaval se producen todo tipo de inversiones de manera que quienes tenían el poder se convierten en esclavos y viceversa, por un corto periodo de tiempo. Este "mundo al revés" presenta el mundo real desde perspectivas alegres, 
humorísticas y risibles, pero también sarcásticas e irónicas. El texto de Hernández desde mi lectura no alcanza a ser carvalesco, sino paródico, a partir de las perspectivas ya señaladas.

32. Escritor ecuatoriano vanguardista (1906-1947).

33. El DRAE señala que el caníbal es 1. "antropófago". 2. "Se dice de los salvajes de las Antillas que eran tenidos por antropófagos". y 3. "Dicho de un hombre cruel y feroz". En cuanto a antropófago indica que es: "Dicho de una persona: Que come carne humana".

34. De acuerdo con el DRAE, en su primera y quinta acepción para la palabra monstruo.

\section{Bibliografía}

Abbagnano, N. (1974). Diccionario de Filosofía. México: Fondo de Cultura Económica.

Bajtín, M. (1999). La cultura popular en la Edad Media y en el Renacimiento. Madrid: Alianza Editorial.

Baudrillard, J. (2007). Cultura y simulacro. Barcelona: Editorial Kairos.

Bocutti, A. (2008). Humorismo y fantástico en la microficción argentina: Raúl Brasca, Rosalba Campra, Ana María Shua. Amoxcalli. 1, 223-239.

Bravo, V. A. (1998). La irrupción y el límite. Hacia una reflexión sobre la narrativa fantástica y la naturaleza de la ficción. México: Universidad Nacional Autónoma de México.

Bravo, V. A. (2005). El miedo y la literatura. Anales de Literatura Hispanoamericana. 34, 13-17.

Caamaño, V. (2013). Seres monstruosos y cuerpos fragmentados. Sus representaciones en dos relatos fantásticos de Alberto Chimal. Revista de Filología y Lingüística. 39 (1), 159-178.

Caamaño, V. (2014). Acercamientos y controversias sobre el estudio de la literatura fantástica actual. Revista de Filología y Lingüística. 40 (1), 15-24.

CEPAL. (1999). El Salvador: Tendencias en lo económico, educativo y salud 1980-1996. [pdf.]. [Elaborado por José Francisco Lazo]. http://www.cepal.org/ [Consulta 28 de abril de 2014].

CEPAL. (2002). El Salvador. [pdf.]. http://www.cepal.org/ [Consulta 28 de abril de 2014].

Chevalier, J. (1995). Diccionario de los símbolos. [Con Alain Gheerbrant]. Barcelona: Editorial Herder.

Comisión de la Verdad para El Salvador. (s.f). De la Locura a la Esperanza: la guerra de los Doce Años en El Salvador: Reporte de la Comisión de la Verdad para El Salvador. [pdf.]. http://www.uca.edu.sv/publica/idhuca/cv.pdf [Consulta 28 de abril de 2014].

Cortázar, J. (1972). Del Sentimiento de lo fantástico. La vuelta al día en ochenta mundos. Tomo I. (69-71). Madrid: Sigo XXI de España Editores.

Freud, S. (1980). Introducción del narcisismo. Obras Completas. (Vol 14). Buenos Aires: Amorrortu Editores.

Freud, S. (1981). Lo siniestro. Obras completas. (Tomo III). Madrid: Biblioteca Nueva.

Fonseca, E. (1998). Centroamérica: su historia. San José: FLACSO: EDUCA.

Foucault, M. (2011). Los anormales. (Curso en el College de France (1974-1975)). Buenos Aires: Fondo de Cultura Económica. 
Gairaud-Ruiz, H. (2013). Subalternidad, Exclusión y Violencia: La construcción de subjetividades en la obra literaria de Claudia Hernández. (Tesis doctoral). Universidad de Costa Rica.

Haas, N. (2009). Ficciones que duelen: Literatura y violencia posconflicto en Centroamérica. Ponencia en el marco del proyecto internacional Hacia una Historia de las Literaturas Centroamericanas. CIICLA, UCR. http://istmo.denison.edu/ [Consulta 30 de abril de 2014].

Hernández, C. (2007). Hechos de un buen ciudadano I. Hechos de un buen ciudadano II. De fronteras. (15-20). (37-42). Guatemala: Editorial Piedra Santa.

Hutcheon, L. (1993). La política de la parodia postmoderna. (Navarro, D., tr.). Criterios. (Edición especial de homenaje a Bajtín), 187-203.

Jackson, R. (2001). Lo 'oculto' de la cultura. Por D. Roas (Comp.). Teorías de lo fantástico. (141-152). Madrid: Arco/Libros, S. L.

Manzoni, C. (2000). Una estética de la ruptura. Por W. H. Corral (Coord.). Pablo Palacio. Obras completas. (447-464). Madrid: ALLCA XX.

Markovic, A. (2008). Lo fantástico y las normas socio-culturales. Amoxcalli. (1), 109-124.

Menjívar, R. (2007, 21 de junio). Claudia Hernández o la renovación del cuento. [Mensaje 1]. http://lamanchaenlapared.blogspot.com/ [Consulta 05 de abril de 2014].

Menjívar, R. (2006, 29 de mayo). Olvida uno. [Mensaje 23]. http://menjivar.blogspot. com/2006/05/olvida-uno.html [Consulta 05 de abril de 2014].

Proner, C. (2012, 02 de abril). Heridas abiertas en El Salvador. Diario digital Contrapunto. http://www.archivoscp.net/2008-2012/ [Consulta 10 de febrero de 2014].

Quiñones, M. (2013). La muerte violenta: Una perspectiva infantil en dos cuentos de Silvina Ocampo. Hispanet Journal. 6, 1-15. http://www.hispanetjournal.com/ [Consulta 25 de abril de 2014].

Roas, D. (2001). La amenaza de lo fantástico. Teorías de lo fantástico. (7-44). Madrid: Arco/ Libros, S. L.

Roas, D. (2011). Tras los límites de lo real. Una definición de lo fantástico. Madrid: Editorial Páginas de Espuma.

Rodríguez-Corrales, C. (2012). Cuerpos desgarrados: textualidades desgarradoras. Una aproximación a la escritura de Claudia Hernández. Revista de Filología y Lingüística. 39 (1), 117-130.

Rojas-González, J. P. (2014). Hechos de un buen ciudadano de Claudia Hernández. La naturalización de "lo fantástico". Káñina. 38 (1), 43-55.

Todorov, T. (2006). Introducción a la literatura fantástica. Buenos Aires: Paidós.

Tortosa-López, J. M., y Crespo-Alonso, S. (2011). Conceptos básicos de patología forense. Estados Unidos: Palibrio. 